\title{
Barreiras e paradigmas na oferta de disciplinas que são puramente presenciais em relação às disciplinas ofertadas à distância em campus da UFSM
}

\author{
Barriers and paradigms in the offer of disciplines that are purely presential \\ in relation to education distance disciplines offered at the campus of the Federal Univesity of Santa Maria. \\ Jose Cardoso Sobrinho', Mônica Elisa Pons², Andreia Vedoin Cielo³ \\ ' Unidade Descentralizada de Educação Superior da UFSM em Silveira Martins - UDESSM- Engenharia Agrícola \\ ${ }^{2}$ Unidade Descentralizada de Educação Superior da UFSM em Silveira Martins - UDESSM \\ ${ }^{3}$ Unidade Descentralizada de Educação Superior da UFSM em Silveira Martins - UDESSM - Educação
}

\section{Resumo}

No decorrer do segundo semestre de 2012, foi ministrada na Unidade Descentralizada de Educação Superior da UFSM em Silveira Martins (UDESSM) - Campus da UFSM em Silveira Martins a disciplina UDSM1034 - Fundamentos Instrumentais para a Gestão, totalmente na forma EAD. A disciplina foi ministrada nos cursos de Bacharelado em Administração e Curso Superior de Tecnologia em Agronegócio. Os alunos matriculados em Administração eram 30 e no de Tecnologia em Agronegócio foram 23. Foi também realizado um levantamento junto aos servidores da UDESSM no que tange ao tema EAD. Em razão disto, foi aplicado um questionário solicitando ao entrevistado se o mesmo tinha conhecimento de alguns itens a respeito à EAD. As respostas obtidas durante a aplicação do questionário foram transcritas de forma integral para o enriquecimento do trabalho. Desta forma, foi realizada a revisão de português apenas preservando as respostas na íntegra. Dentre os 36 servidores da UDESSM (docentes e TA's) foram sorteados sete para a entrevista. Pôde-se concluir que as pessoas entrevistadas não conhecem totalmente a forma de funcionamento de cursos que atuam em EAD e que há necessidade de um trabalho de conscientização a respeito do assunto, a comunicação entre professores e alunos via Moodle foi imprescindível para a condução da pesquisa em relação à condução da disciplina UDSM1034, o acesso ao portal Moodle da UFSM é simplificado e fácil de operar.

Palavras-chaves: EAD, Moodle, Agronegócio

\begin{abstract}
During the second half of 2012 it was conducted in Unit Decentralized Higher Education of UFSM Silveira Martins (UDHESM) - Campus UFSM in Silveira Martins discipline UDSM1034 - Instrumental Foundations for Management, totally in shape EAD. The course was taught in the courses of Bachelor of Administration and Technology Degree in Agribusiness. The numbers of students enrolled in Management of Technology were 30 and Agribusiness 23. It was also conducted a survey among the servers of UDESSM regarding the theme EAD. Because of this it was a questionnaire asking the respondent if him was aware of a few items about the EAD. The answers obtained during the questionnaire were transcribed in full for job enrichment, it was performed a review of the Portuguese only, preserving the answers in full. Among the 36 servers of UDESSM (professors and TA's) were drawn seven to the interview. It was concluded that people interviewed do not fully know how to run courses that work on EAD, it is necessary an awareness work about the subject, the communication between teachers and students through Moodle was essential for the conduction of research regarding the conduct of the discipline UDSM1034, the access of the portal Moodle UFSM is simplified and easy to operate.
\end{abstract}

Keywords: EAD, Moodle, Agribusiness 


\section{INTRODUÇÃO}

A educação a distância é uma modalidade de educação que vem ganhando cada vez mais espaço, pois é vista como uma solução para os problemas relacionados com a formação inicial e também com a formação continuada de profissionais das mais diferentes áreas. Através dela, é possível aprender continuamente, mesmo estando no mercado de trabalho, pois o aluno pode estabelecer a sua própria rotina de estudo. Além disso, a educação a distância proporciona o acesso à educação à população que reside em locais afastados dos grandes centros de ensino, que possui poucos recursos financeirose que não teriam condições de frequentar presencialmente as aulas. Percebem-se ainda resistência e preconceito em relação à $E A D$, mas não se pode negar que, a partir da educação a distância, é possível oferecer oportunidades iguais à população, superando a defasagem educacional no Brasil.

Cada vez mais pessoas têm acesso à EAD, pois ela está crescendo em todas as áreas e a evolução do sistema é notória. Atende um maior número de pessoas ao mesmo tempo, com baixo custo e consegue atingir os objetivos específicos de cada um. Pode-se aprender de diferentes lugares, regiões, juntos e separados.

No entanto, essa modalidade de educação traz consigo inúmeros desafios para os envolvidos no processo de ensino-aprendizagem, pois modifica as formas de ensinar e aprender. $\mathrm{Na} E A D$, os alunos ganham autonomia em relação a sua aprendizagem e precisam administrar o seu tempo de estudo, a fim de participarem ativamente da construção do conhecimento, a partir da interação com os envolvidos no processo educativo. Alguns estão preparados para essas mudanças, mas muitos não, pois é realmente difícil alterar padrões já cristalizados nas organizações e na sociedade.

Mesmo com a tecnologia de ponta, percebem-se ainda dificuldades em romper com as práticas tradicionais de ensino-aprendizagem como transmissão de informação e passividade do aluno. Nesse sentido, há ainda muito que avançar em relação à elaboração propostas que priorizem a construção do conhecimento e a interação.

Por outro lado, muitos avanços já podem ser percebidos. Atualmente, já se pode perceber que há um esforço em associar a atividade individual com a possibilidade de comunicação instantânea, favorecendo a aprendizagem cooperativa. Além disso, é importante ressaltar que a educação a distância tem influenciado positivamente a presencial, pois esta tem utilizado metodologias semipresenciais, flexibilizando tempos e espaços de aprendizagem e inovando currículos, formas de dar aula e de avaliar.

Com isso, observa-se que as instituições educacionais, de um modo geral, e as instituições de ensino superior, de maneira específica, buscam integrar o ensino presencial e a distância, a fim de otimizar as equipes de trabalho, as metodologias, o conteúdo, o marketing e a infraestrutura. Essa integração pode se constituir em uma alternativa importante para oferecer um ensino de qualidade, inovador e com baixo custo.

Vive-se numa sociedade que passa por constantes transformações, a qual é marcada pelo dinamismo entre as relações políticas, econômicas e sociais. Há um reconhecimento quanto à importância da estratégia da educação e das tecnologias de informação para o desenvolvimento acadêmico, tecnológico, institucional e o humano de forma geral. Como dizem os neurologistas, nós nascemos com muitas habilidades, outras devemos ser treinados para trabalhar com ela. É muito importante que em contextos educacionais sejamos instrumentos modificadores de relacionamentos, de produção e de distribuição de conhecimentos. Além disto, pensamos que somos professores e, sobretudo, educadores, o que é a tarefa mais difícil, quase impossível, para muitas pessoas (Brasil, 2008). Ser professor e educador são tarefas árduas que exigem muito mais que conhecimento e passagem de conteúdo aos estudantes, precisa-se aprender a aprender. As demandas educacionais neste início de século indicam uma mudança de paradigmas que veem atreladas a um conjunto de exigências, para que se faça frente às necessidades da cidadania moderna, da evolução e revolução de novas tecnologias e informação, comunicação, educacionais e até da ética nas relações sociais.

As altas velocidades de transmissão de dados oferecem muitos benefícios para as organizações, dos quais se destacam a conectividade, o alcance global, redução dos custos de comunicação, redução de custo de transação, redução de curso de operação, interatividade, flexibilidade e personalização e distribuição acelerada do conhecimento (Amor, 2000; Laucon e Laudon, 2001).

Entretanto, Young (2001) observa que as oportunidades mais promissoras que a Internet pode oferecer são as operações dos negócios das organizações, a entrega do aprendizado e o suporte para a performance dos empregados. Rosenberg (2002) afirma que a Internet é uma tecnologia unificadora que permite que o aprendizado ultrapasse as fronteiras geográficas e organizacionais, as culturas e fusos horários, as linhas de produtos e classifi- 
cação de clientes, transformando radicalmente o aprendizado nas Universidades e organizações e levando todos os envolvidos a avaliar novamente a sua função e seu objetivo. São colocações que provocam as Universidades, sobretudo aquelas que ainda não estão completamente envolvidas na modalidade de ensino a distância, Ghedine (2006)

$\mathrm{Na}$ UFSM, os cursos de graduação fazem, na maioria, aulas presenciais, uma vez que os cursos são essencialmente desta forma, contudo, ações que levam docentes a ministrarem aulas de forma presencial e a distância, as duas formas ao mesmo tempo, ainda são incipientes, embora haja flexibilidade na maioria dos projetos pedagógicos que esta atividade seja feita em $20 \%$ das disciplinas nos cursos de graduação. Isto ocorre porque os cursos ou são na sua totalidade ministrados a distância ou na forma presencial, e ainda falta a cultura de se atuar na forma de educação á distância nas disciplinas que ministramos presencialmente. $\mathrm{O}$ acadêmico quando cursa disciplina sem estar presente na sala, o seu sucesso dependerá dele e da Universidade, mas a questão não é somente esta, pessoas com sucesso no método de ensino a distância levarão para as empresas onde forem trabalhar a metodologia que usou na instituição de ensino superior. Diante do exposto, este trabalho objetivou:

1 - Avaliar a sensibilidade do grupo de servidores da Unidade Descentralizada de Educação Superior da UFSM em Silveira Martins em relação ao tema EAD.

2 - Ofertar uma disciplina na forma de EAD para dois cursos da UDESSM.

\section{METODOLOGIA}

É imprescindível que a educação ocupe novamente o lugar de destaque nas linhas de ação de desenvolvimento das nações, seja de acordo com o impacto tecnológico sobre a organização do trabalho, atividades acadêmicas ou em decorrência da rápida disseminação das tecnologias de transmissão de dados com o desenvolvimento de redes com grandes capacidades de transmissão de dados.

Durante o segundo semestre de 2012, foi ministrada na UDESSM a disciplina UDSM1034 - Fundamentos Instrumentais para a Gestão totalmente na forma EAD. A disciplina foi ministrada nos cursos de Bacharelado em Administração e Curso Superior de Tecnologia em Agronegócio. Os alunos matriculados em Administração eram 30 e no de Tecnologia em Agronegócio foram 23.
Foi aplicado um questionário solicitando ao entrevistado se o mesmo tinha conhecimento de alguns itens a respeito à $\mathrm{EAD}$, os itens estão descrito a seguir:

O que é EAD?

Para que serve EAD?

Quando você tomou conhecimento da existência de EAD?

Você hoje tem o mesmo conceito de quando tomou conhecimento de EAD?

Sabe da política educacional do EAD hoje?

Como definir Qualidade em EAD? em EAD?

Sabe quais são os indicadores de qualidade

Se for coordenador de curso, poderia responder quantas horas em EAD há no curso que coordena? ciente?

A aprendizagem do aluno distante é efi-

Você considera a educação à distância como opção estratégica para o Brasil?

Você considera relevante a integração entre o ensino presencial e a distância?

Visando dar integridade às respostas dos entrevistados selecionados (sorteio) entre os 36 servidores da UDESSM transcreveram-se as respostas de cada entrevistado, fazendo somente a correção de linguagem.

O plano de ensino da disciplina ministrada à distância foi aquele padronizado pela Coordenação de Curso da UDESSM - UFSM Campus Silveira Martins, conforme a seguir:

\section{PLANO DE ENSINO}

Disciplina: 1034 - Ferramentas instrumentais para gestão

Ano/Semestre: 2012 /2

Carga horária/créditos: 60 / 4

Professor(es): Dalva Maria Righi Dotto

David de Lorenzi Junior José Cardoso Sobrinho

Objetivos - Desenvolver competências sobre instrumentos de gestão com a finalidade de complementar as disciplinas dos cursos afins.

\section{Métodos e recursos utilizados}

Plataforma moodle - ensino a distância Fóruns

\section{Avaliação}

Participação - acessos ao conteúdo: 20\%

Participação nos fóruns: $20 \%$

Atividades propostas: $40 \%$

Avaliação presencial final: $20 \%$ 
Conteúdo programático

UNIDADE 1 - FERRAMENTAS INSTRUMENTAIS PARA A GESTÃO

- Princípios básicos instrumentais para a utilização da ferramenta MOODLE;

- Princípios básicos para a utilização de Excel;

UNIDADE 2 - PRICÍPIOS BÁSICOS DE ADMINISTRAÇÃO

2.1. Estratégia de Empresas

2.1.1 - Case

2.2. Gestão de pessoas

2.2.1 - Case

2.3 Marketing

2.3.1 - Case

2.4 Produção

2.4.1 - Case

2.5 Economia e finanças

2.5.1 - Case

2.6 Internacionalização

2.6.1 - Case

2.7 Sistema de informações

2.7.1 - Case
Referência bibliográfica relativa á disciplina ministrada.

LEAL., B. A. Gestão de Custos e Formação de Preços : Com Aplicações na Calculadora HP 12C e excel. $5^{\text {a }}$ Ed. São Paulo: Atlas, 2008.

LEAL., B. A. Minhas aulas de custos, finanças, contabilidade e metodos quantitativos [CD]. São Paulo: Atlas, 2004.

LAPPONI, J. C. Estatistica usando Excel . Campus/Elsevier, quarta edição, 2005.

LAPPONI, J. C. Estatistica usando Excel [CD]. Campus/Elsevier, 2004.

TYBUSCH, J. S. ALBERTI, T. F. Introdução à Modalidade EaD - http://www. ufsm.br/. UFSM, 2012

estudo foi:

O cronograma da disciplina objeto de

Cronograma das aulas

\begin{tabular}{|l|l|l|}
\hline Aula & Mês & Conteúdo Programático \\
\hline 01 & $10 / 2012$ & Introdução à computação \\
\hline 02 & $10 / 2012$ & Redes de computadores e a internet \\
\hline 03 & $11 / 2012$ & Ambiente virtual de ensino-aprendizagem (AVEA) e Internet 2.0 \\
\hline 04 & $11 / 2012$ & Ambientes virtuais de aprendizagem \\
\hline 05 & $11 / 2012$ & Mobile learning (m-learning) \\
\hline 06 & $11 / 2012$ & Ambientes virtuais de aprendizagem (AVAs) \\
\hline 07 & $12 / 2012$ & O aspecto relacional das interações na Web 2.0 \\
\hline 08 & $12 / 2012$ & $\begin{array}{l}\text { Princípios básicos de administração - cases: } \\
\text { (a) Estratégia de Empresas; (b) Gestão de pessoas. }\end{array}$ \\
\hline 09 & $12 / 2012$ & $\begin{array}{l}\text { Princípios básicos de administração - cases: } \\
\text { (a) Marketing; (b) Produção }\end{array}$ \\
\hline 10 & $01 / 2013$ & $\begin{array}{l}\text { Princípios Básicos De Administração - cases: (a) Internacionalização; (b) Sistema } \\
\text { de informações. }\end{array}$ \\
\hline 11 & $01 / 2013$ & Excel \\
\hline 12 & $01 / 2013$ & Excel \\
\hline 13 & $01 / 2013$ & Excel \\
\hline 14 & $02 / 2013$ & Excel \\
\hline 15 & $02 / 2013$ & Excel \\
\hline 16 & $02 / 2013$ & Avaliação presencial \\
\hline
\end{tabular}




\section{RESULTADOS E DISCUSSÃO}

Foram compiladas as melhores respostas em cada pergunta. Os resultados estão apresentados a seguir:

\section{Questionário a respeito de EAD}

\section{1) O que é EAD?}

R1 - O ensino a distância, ou educação a distância, como o próprio nome já diz, é uma modalidade de estudo não presencial, viabilizada por diferentes meios de comunicação.

R2 - EAD é Ensino a Distância, significa o processo de ensino e aprendizagem que não envolve presença física do professor e do aluno.

R3 - Educação à distância, que proporciona ou melhor elimina barreiras geográficas entre aluno e professor.

R4 - Educação à distância, onde o professor e o aluno podem estar interligados pela internet ou por outras tecnologias semelhantes de comunicação à distância (TICs).

R5 - Educação à distância.

R6 - É uma modalidade de educação não presencial ou semi-presencial que consiste em o professor e o aluno copartilharem materiais de estudo e interagirem com o uso de TI. Nesse processo de interação e compartilhamento, ocorre a aprendizagem.

\section{2) Para que serve EAD?}

R1 - Principalmente para possibilitar a formação e o estudo ao público que, por algum motivo, não pode ou não tem interesse em frequentar aulas tradicionais/presenciais (por questões de deslocamento, perfil, etc.). Mas também é um recurso a ser utilizado em conjunto com outras modalidades de ensino, uma vez que promove uma aproximação entre alunos, professores, tutores, pesquisadores, interessados em uma área comum e permite a utilização de uma série de ferramentas que potencializam o ensino.

Naturalmente, o EAD não se aplica apenas ao ensino formal. Qualquer prática que envolva troca de conhecimento pode se valer desse formato. Treinamentos, cursos, etc.

$\mathrm{R} 2$ - A EAD serve para o processo de formação. No meu ponto de vista tem maior importância na formação continuada dos indivíduos.

R3 - Possibilita a expansão e a interiorização do ensino superior público de qualidade.

R4 - Possibilita a expansão e a interiorização do ensino superior público de qualidade, aumentando o número de pessoas que possam realizar o ensino superior.

R5 - Levar educação formal e conhecimento complementar aos mais longínquos lugares do País, de modo a democratizar o acesso ao ensino público, de qualidade e gratuito.

R6 - Entre outras coisas, ampliar o espaço-tempo de estudo, permitindo que alunos, professores e demais partícipes no processo de ensino-aprendizagem possam interagirem entre eles e com o conhecimento em qualquer lugar e horário.

R7 - A EAD serva para driblar a distância entre os atores da educação (professor e aluno). De um lado, há crescente exigência no mundo contemporâneo quanto à mobilidade; de outro, ao mesmo tempo crescentes aumentos de obstáculos a essa mobilidade (ruas congestionadas, estadas perigosas, etc.). Assim, a EAD vem ao encontro de o aluno estudar sem precisar estar presente fisicamente na sala de aula. Além disso, a EAD não consiste somente em atividades à distância (há avaliações presenciais), em que pese o fato de que tais atividades são as mais expressivas em termos de tempo.

3) Quando você tomou conhecimento da existência de EAD?

R1 - Há 15 anos, mais ou menos, por meio do Instituto Universal Brasileiro.

R2 - Quando começaram a serem oferecidas as primeiras disciplinas a distância nos cursos presenciais na universidade em que trabalhei o que remonta ao ano de 2008.

R3- No ano de 2009, quando realizei um curso de formação de professores na Universidade Federal de Santa Maria.

R4- No ano de 2009, quando realizei um curso de formação de professores na Universidade Federal de Santa Maria.

R5 - Quando começaram os debates nacionais a respeito da matéria, tanto pelo congresso nacional quanto pela sociedade organizada (representações).

R6 - Não sei precisar, mas há vários anos.

R7 - Tomei conhecimento por meio de anúncios publicitários, inicialmente. Mais tarde, começaram as atividades de EAD na Universidade em que eu ministrava aulas (UCS). Fiz uns dois cursos sobre EAD.

4) Você hoje tem o mesmo conceito de quando tomou conhecimento de EAD?

R 1 - Não. Há alguns anos, EAD parecia algo muito limitado, com diversos obstáculos para a troca de informação. A internet revolucionou 
o EAD, e o leque de possibilidades que se disponibiliza hoje não pode ser comparado ao que havia antes.

R 2 - Não. Hoje entendo melhor a contribuição que o ensino a distância pode oferecer aos alunos.

R3 - Não, tinha um conceito simplificado antes do contato.

R4 - Não.

R5 - Não, pois atualmente acredita-se que essa modalidade é uma alternativa a quem está distante dos grandes centros de ensino.

R6 - Obviamente não. No início via a EAD como uma tapeação para se conseguir certificados. Hoje, vejo que a qualidade do curso não está apenas vinculada ao projeto do curso ser ou não ser presencial. Existem bons e maus cursos de EAD, tanto quanto os presenciais.

R7 - Não tenho o mesmo conceito de outrora. Meu conceito atual de EAD é que se tatá de um eficiente mecanismo de criação de capital humano e de educação, desde que professor e aluno se comprometam na aprendizagem e nas atividades e tarefas (isso também é válido para o ambiente presencial de sala de aula). O domínio dos recursos de TI é fundamental. hoje?

5) Sabe da política educacional do EAD

R1 - Não.

R2 - Desconheço a atual política educacional da EAD.

R3 - Sim

$\mathrm{R} 4-\mathrm{Sim}$

R5 - Apenas o suficiente para compreender o método, sem muitos detalhes acerca do conteúdo. R6 - Não.

R7 - Não conheço a atualidade do sistema.

6) Como definir Qualidade em EAD?

R 1 - Plataformas robustas, estáveis e fáceis de usar; professores comprometidos e preparados para a modalidade de EAD; tutores e suporte disponíveis sempre que necessário; conteúdo e atividades pensadas, planejadas e desenvolvidas especialmente para EAD, com a utilização do maior número possível de mídias; currículo estruturado com a maior flexibilidade possível; avaliação constante dos alunos; aproximação entre professores e tutores.

R 2 - A qualidade pode ser definida pelo comprometimento dos envolvidos no processo, começando pelos gestores e professores não tomando a EAD apenas como forma de aumentar o número de formados.
R3 - Por meio da capacitação dos professores e tutores, na abrangência dos cursos ofertados, na qualidade da TICs aplicadas, nos materiais didáticos utilizados e na infra-estrutura disponível.

R4 - Por meio da capacitação dos professores e tutores, na abrangência dos cursos ofertados, na qualidade da TICs aplicadas, nos materiais didáticos utilizados e na infra-estrutura disponível.

R5- Não tenho embasamento para responder esta questão.

R6 - Como em cursos presenciais um curso será de qualidade se permitir aos seus alunos uma reflexão e um posicionamento crítico acerca da realidade que o cerca, permitindo a atuação e posicionamento independentes sobre as questões que envolvem a sociedade.

R7 - Uma definição poderia ser: "aprender bem o que se espera aprender no âmbito da disciplina, entendendo-se apreender como ser aprovado nos testes que tentem o que precisa aprender".

7) Sabe quais são os indicadores de qualidade em EAD?

R 1 - Não.

R 2 - Desconheço.

R3 - Sim

R4 - Não

R5 - Acredita-se que sejam, em parte, os mesmo da modalidade presencial, identificados pelo ENADE e auditoria do MEC.

R6 - Não.

R7 - Não conheço as atualidades sobre o tema.

8) Se for coordenador de curso, poderia responder quantas horas em EAD há no curso que coordena?

Atualmente não é ofertada, mas estamos dialogando sobre a possibilidade de integrar disciplinas presenciais com o EAD.

9) A aprendizagem do aluno distante é eficiente?

R 1 - A aprendizagem, para ser eficiente, independe do modelo de ensino utilizado, desde que sejam atendidas as expectativas do aluno e sejam oferecidas todas as condições necessárias à sua autonomia enquanto estudante. Cabe lembrar, no entanto, que, em alguns casos, o perfil do aluno de EAD não é o mesmo do aluno presencial, e a forma como a formação via EAD funciona difere daquela como ocorre a presencial.

R 2 - Não tenho como afirmar. O que poderia esclarecer essa questão são pesquisas comparativas entre os cursos que possuam formação 
a distância e também presencial.

R3 - Acredito que sim.

R4 - Sim

R5 - Depende do método de ensino da cada docente envolvido.

R6-Depende um pouco do aluno (questões como autodisciplina e motivação), mas poderá ser sim eficiente.

R7 - A eficiência, com ojá dito, depende do grau de comprometimento do professor e do aluno, da condição desafiadora das atividades, tarefas e avaliações, do gosto do aluno pela matéria; em suma, como a aprendizagem é um processo complexo por definição, imagina-se não haver resposta definitiva para o que se entende por eficiência na aprendizagem EAD.

10) Você considera a educação à distância como opção estratégica para o Brasil?

R 1 - Sim, desde que o objetivo a ser perseguido seja a formação qualificada e a excelência em ensino. Aumentar a oferta de vagas em instituições públicas de ensino, por exemplo, é, indiscutivelmente, uma boa razão para investir tempo e dinheiro em EAD. Contudo, se for puramente para maquiar estatísticas, é um tiro no pé.

R 2 - Não considero como opção estratégica, mas sim como apoio ao ensino presencial e para formação continuada.
R3 - Sim

R4- Sim, pois possibilita que o ensino superior esteja ao alcance de uma parcela significativa da população brasileira, de forma gratuita e com qualidade, desenvolvendo áreas estratégicas para um crescimento e desenvolvimento social e econômico mais justo.

R5 - Sim, porque geram economicidade, democratização do ensino público e possibilita a inserção tecnológica e o acesso à informação.

R6 - Sem dúvida alguma. Há ainda muito que se evoluir nesta modalidade, mas é uma estratégia de grande valia.

Sem dúvida, pois como dito já mencionado, a EAD é central na superação de distância física. Como o Brasil possui dimensões continentais, lugares como na Região Norte que possuem rios e florestas, o acesso à educação via EAD é central para através da criação de capital humano, o Brasil com esta modalidade de ensino crescerá muito em sua produtividade e por consequência, desenvolvimento social e econômico.

11) Você considera relevante a integração entre o ensino presencial e a distância?

R 1 - Certamente. E não vejo motivos para que essa integração não aconteça.

R 2 - Acho fundamental nos tempos atuais a integração entre o ensino presencial e a distância,

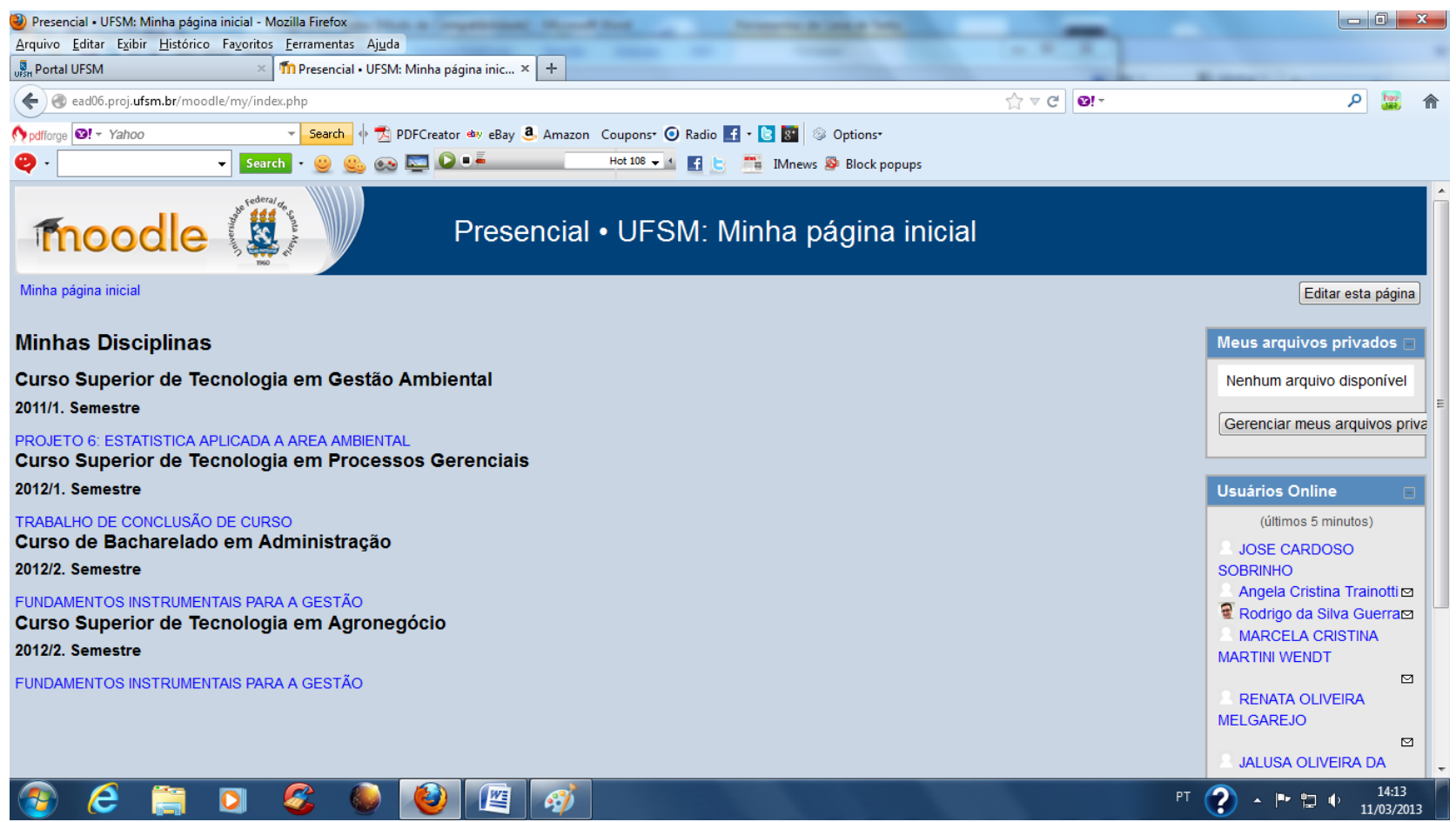

Figura 1 - Representação da página inicial no Moodle. 


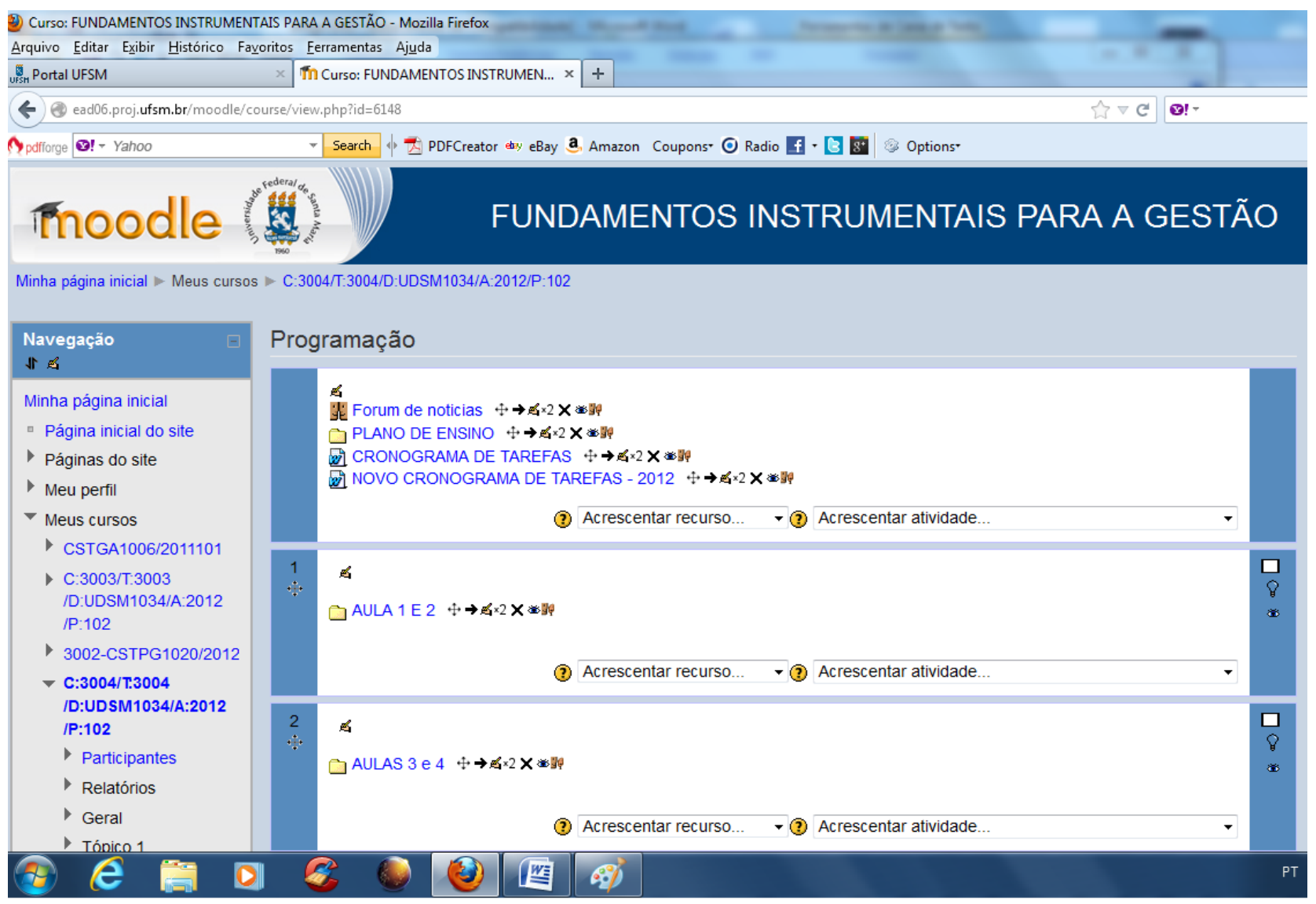

Figura 2 - Representação da disciplina editada no Moodle pronta para inserir dados pelo professor.

principalmente o EAD côo apoio ao presencial.

R3 - Sim e acredito ser uma necessidade.

R4- Sim. Considero muito importante a integração entre o ensino presencial e a distância, pois possibilita um dinamismo maior nas atividades de ensino-aprendizagem. Além de desenvolver um espírito investigativo dos alunos.

R5 - Sim, porque, como o EAD é uma modalidade mais moderna e tecnológica, pode contribuir na formação do aluno de forma mais ampla e eficiente.

R6 - É fundamental e isto tornará o Brasil mais eficiente e competitivo em termos de tecnologias, de conhecimento e por que não de cidadania.

R7 - Pensa-se que essa integração é ótima, pois a presencial quando conduzida de forma muito tradicional é pouco estimulante, e a EAD pura também, muito distante compromete a sociabilidade. Um tempero, uma ponderação entre ambas pensa-se que pode ser gerada uma modalidade híbrida e muito mais desejável.

Pelos resultados das respostas verifica-se que conscientização do grupo variou no que tange ao assunto $\mathrm{EAD}$, contudo é um tema que necessita ser mais trabalhado para que sejam vencidos alguns preconceitos que o tema possa enfrentar quando da efetivação de atividade acerca do assunto.

Em relação à disciplina UDSM1034 - Fundamentos Instrumentais para a Gestão, ministradas totalmente na forma EAD as Figuras $1 \mathrm{e}$ 2 , apresentam as atividades inseridas no sistema Moodle da UFSM. É um sistema prático e bem fácil de ser trabalhado tanto pelo professor quanto pelo estudante da disciplina.

\section{CONCLUSÕES:}

Considerando o exposto e os resultados obtidos, pode-se concluir que:

- As pessoas entrevistadas não conhecem adequadamente os cursos EAD;

- Há necessidade de trabalho de conscientização a respeito do assunto;

- A comunicação entre professores e alunos via Moodle foi imprescindível para a condução do projeto;

- O acesso ao portal Moodle é bastante simplificado; 


\section{AGRADECIMENTOS.}

Ao Núcleo de Tecnologia à Distância (NTE) pela concessão da bolsa de pesquisa e pelo apoio durante a condução da pesquisa.

Agradeço também aos servidores da UDESSM que prontamente responderam ao questionário quando da sua aplicação.

\section{RefERÊnCIAS BIBLIOGRÁficas}

AMOR, D., A (R)evolução do E-Business Vivendo e Trabalhando em um Mundo Interconectado. Editora Makron Books. São Paulo, 2001.

BRASIL, 2008. Ministério da Educação. Plano Nacional de Formação de Professores do Estado do Pará - PARFOR/PA. Instituto Federal De Educação, Ciência e Tecnologia do Pará. 2008. Belém - PA. 92p.

GHEDINE, T.; TESTA M. G.; FREITAS, H. M. R.. Compreendendo as iniciativas de educação a distância via internet: estudo de caso em duas grandes empresas no Brasil. Rev. Adm. Pública [online]. 2006, vol.40, n.3, pp. 427-455. ISSN 0034-7612.

LAUDON, K. C.; LAUDON, J. P. Gerenciamento de sistemas de informação. Rio de Janeiro: LTC, 2001.

ROSENBERG, M. J. E-learning: estratégia para a transmissão do conhecimento na era digital. São Paulo: Makron Books, 2002.

YOUNG, $\mathrm{K}$. The effective deployment of e-learniny. Industrial and Commercial Traininy, v. 33, n. 1, p. 5-11, 2001. 